\title{
Genetic Testing for Hereditary Gynaecological Cancer: An important and a New Avenue for developing Countries Genetic
}

\author{
Hanoon P Pokharel \\ Department of Obstetrics and Gynaecology \\ Birat Medical College and Teaching Hospital, Kathmandu University
}

Received: 5 December 2018; Accepted: 20 December 2018

DOI: 10.3126/njog.v13i3.23422

\section{ABSTRACT}

Aims: To explore the scope of genetic testing for gynecological cancer in Nepal.

Methods: Review of genetic testing methods and assessment of facilities and barriers within the country.

Results: Country's resources are still limited but the genetic testing cost is decreasing substantially. Gynecological service providers are increasing to provide services who can be the appropriate candidates to acquire training on genetic testing

Conclusions: Hereditary cancer diagnosis using stable buccal swab would be feasible with appropriate training.

Keywords: BRCA, developing countries, genetic testing, hereditary gynecological cancer.

\section{INTRODUCTION}

Poor health within countries and inequities between countries are largely caused by the unequal distribution of power, income, goods and services, resulting from a combination of poor social policies, unfair economic arrangements and bad politics. ${ }^{1}$ Cancer has historically been given low priority in developing countries. Only $5 \%$ of global spending on cancer is directed towards developing countries, which have $80 \%$ of the world's population. ${ }^{2}$ By 2020 , the International Agency for Research on Cancer, a branch of the World Health Organization, predicts 16 million new cases of cancer per year, with cancer overtaking heart disease to become the world's number 1 killer. Currently $12.5 \%$ of all deaths are caused by cancer, which is more than HIV/acquired immunodeficiency syndrome (AIDS), tuberculosis, and malaria combined. ${ }^{3}$ In 2014 , the leading causes of cancer mortality in women in Nepal were cervical $(18.4 \%)$, breast $(11.6 \%)$, endometrial $(9.5 \%)$ and ovarian cancer $(7 \%) .{ }^{4}$ Despite a significant cancer incidence and mortality, Nepal has yet to establish an operational cancer policy, strategy or action plan. A cancer registry supported by the World Health

\section{CORRESPONDENCE}

Dr Hanoon P Pokharel

Department of Obstetrics \& Gynecology

Birat Medical College and Teaching Hospital, Kathmandu University Email: hanoon.pokharel@gmail.com, Phone: +977-9852047747
Organization was established in 2005 to collect cancer data from seven major hospitals; however data from much of the country's population remains uncollected. ${ }^{5}$

\section{DISCUSSION}

\section{Hereditary gynecologic cancer}

A gynecological cancer diagnosis may identify women at risk of germline mutations in BRCA1, BRCA2 or in the mismatch repair (MMR) genes. Since the identification of the BRCA1/2 cancer susceptibility genes in 1994, there have been significant advances in our knowledge of the cancer risks for mutation carriers. $^{6,7}$ Meta-analyses indicate that a BRCA1 mutation carries a $47-66 \%$ probability of developing breast cancer and a 35-46\% probability of developing ovarian cancer over a woman's lifetime and with a BRCA2 mutation, it is $40-57 \%$ for breast and $13-$ $23 \%$ for ovarian cancer. ${ }^{8}$

Lynch syndrome, also referred to as Hereditary Non- Polyposis Colorectal Cancer (HNPCC), is an autosomal dominant disease that may lead to colorectal, endometrial, gastric and ovarian cancer. Lynch syndrome is caused by germline mutations in 
DNA mismatch repair (MMR) genes, which include MLH1, MSH2, MSH6 and PMS2. The estimated risk of developing endometrial, colorectal and ovarian cancer for patients with MMR gene mutations by the age of 70 years is $15-30 \%, 25-37 \%$ and $8-15 \%$ respectively. ${ }^{9,10}$ There are considerable variations between risks associated with each gene.

Timely genetic testing of selected patients may influence treatment, enable concurrent or future risk reducing screening and surgery, and provide opportunities for identification of at-risk relatives. ${ }^{11}$ Risk reducing salpingo-oophorectomy is a minimally invasive procedure which not only dramatically reduces ovarian and fallopian cancer risk, but also reduces the risk of breast cancer, particularly if done pre-menopausally. It has been shown to be associated with a lower risk of ovarian cancer, a lower risk of breast cancer, lower all-cause mortality, breast cancer-specific mortality, and ovarian cancer-specific mortality in BRCA1/2 mutation carriers. The most effective single intervention for BRCA1 mutation carriers is salpingo-oophorectomy at age 40 , yielding a $15 \%$ absolute survival gain. ${ }^{12,13}$ Prophylactic hysterectomy with bilateral salpingo-oophorectomy is an effective strategy for preventing endometrial and ovarian cancer in women with Lynch syndrome. ${ }^{14}$ Annual colonoscopy has proven benefits in reducing cancer incidence in mis-match repair mutation carriers. ${ }^{15}$ In resource poor developing nations, these screening and risk-reducing interventions have the potential to reduce the cancer burden in a costeffective manner.

Barriers to implementation of a hereditary cancer identification process in a developing nation

Although there have been recent advances in the availability of genetic testing in many developing countries, there is disparity in skills and knowledge among the health care providers regarding the availability of modern scientific tools, and recognition of the benefits of genetic testing for gynecological cancers. As such, there is a great need for the introduction of further genetic counseling education and hereditary cancer services for gynecological care in Nepal. ${ }^{16}$ However, multiple barriers need to be overcome.

\section{Late presentation}

Limited public awareness of the symptoms of gynecological cancers is a major barrier for the early diagnosis of gynecological cancers in developing nations such as Nepal.

\section{Limited access to specialized services}

There is mal-distribution of health services, with specialized health services being available only in few major cities of the country. There is no access to specialized health care services or diagnostic facilities in other parts of the country. The centers are concentrated within capital city Kathmandu. ${ }^{17}$ Low health literacy with a health literacy rate of $57 \%$ and $66 \%$ in females and males respectively, many Nepalese patients may not have the capacity to obtain and understand the basic health information necessary to be able to make appropriate health decisions. ${ }^{18}$ One of the biggest challenges to improving health outcomes is educating women and empowering them with the health knowledge necessary to seek appropriate health care and make informed decisions. This is particularly relevant with regard to hereditary cancers, as women in developing nations are unlikely to be well informed about opportunities for genetic testing and preventive and risk reducing strategies. Further to this, the outflow of patients going to neighboring India for treatment results in underreporting of cancer cases by family members, and the absence of a standardized central registry further impedes the clinician's ability to obtain an accurate family history. Cultural, religious and traditional health practices persisting secrecy around cancer diagnosis inhibits knowledge of family history, and is a major barrier to the recognition of hereditary cancer syndromes. Traditionally, doctors in Nepal do not discuss a diagnosis of malignancy with their patients. Instead, discussion is more likely to take place with family members, who then filter the information that the patient receives. This is accepted by the professionals in Nepal as an unchallengeable tenet of Nepal's illness culture. ${ }^{19}$ Women diagnosed with cancer may not be in a position to make autonomous decisions about genetic assessment.

\section{Geographical barriers}

The topography of Nepal impedes access to medical services, impacting most on preventive health care and asymptomatic screening. ${ }^{20}$ In developing countries such as Nepal, testing for hereditary cancers 
may be impaired by inadequate infrastructure for the transportation of samples (particularly from remote areas) to high quality laboratories for processing and interpretation.

\section{Economic barriers}

Diagnosed patients may not seek treatment because of financial barriers prohibiting many families from receiving potentially lifesaving treatment. With a per capita income of USD 600, many Nepalese are unable to afford expensive cancer treatments due to the lack of publicly funded health care or proper health insurance. The indirect cost in the treatment process is often overlooked (transport, accommodation and meals). Despite the gradually reducing trend in cervical cancer diagnosis as a result of the Human Papillomavirus (HPV) vaccine in developed nations, cervical cancer remains a priority in developing countries. Along with this, hereditary cancers face significant competition with infectious diseases, maternal mortality and other health needs vying for the limited resources, infrastructures, laboratory facilities and scarcity of qualified health professionals.

Development of educational module screen for care providers

In developing countries, in order to make an impact in the management of gynecological cancer, the treating gynecologist should be trained and skilled in counseling techniques which will ultimately maximize the detection of mutation carriers. The information applies to a relatively small number of patients in any practice, and the evidence base changes rapidly, making it difficult for all but the most specialized providers to stay up to date. In our previous study it was found that approximately $46 \%$ of all clinicians felt prepared to answer patient's questions about genetic testing for gynecologic cancer. However, while $94 \%$ of gynecologic oncologists felt prepared, only $47 \%$ of gynecologists and $26 \%$ of other clinicians did so, despite $86 \%$ of gynecologists and $71 \%$ of other clinicians reporting that patients had asked questions about genetic testing. ${ }^{16}$

\section{CONCLUSIONS}

Although the position of women has improved substantially in Nepal and other developing nations over the past decades, progress has been uneven and multiple challenges remain. Despite great improvements in health in the past 30 years, many women are yet to benefit from these advances in early cancer diagnosis and management. Women's low literacy levels, cultural and religious factors, competing health needs, discriminatory feeding patterns, limited resources, poorly developed health care services, and limited information on cancer prevention are contributory. However, with the rapidly falling cost of genetic testing, the ability to provide DNA from a stable buccal swab, and with appropriate training of gynecological health care providers, there is a potential of extending the benefits of hereditary cancer diagnosis in Nepal.

\section{REFERENCES}

1. Marmot M, Friel S, Bell R, Houweling TAJ, Taylor S. Closing the gap in a generation: health equity through action on the social determinants of health. The Lancet 372(9650):1661-9. DOI:: 10.1016/S0140-6736(08)61690-6.

2. Breast cancer in developing countries. Lancet 2009;374(9701):1567. DOI:: 10.1016/S0140-6736(09)619309

3. Lodge M. The evidence base for cancer control in developing countries: what is to be done? The Newsletter of the International Network for Cancer Treatment and Research. vol. 6: http://www.inctr.org/publications/2005_v06_n03_w02. shtml; 2005. DOI:: 10.1016/j.breast.2011.01.012.

4. Annual report from B P Koirala Memorial Cancer Hospital. 2014.

5. WHO Guidelines Approved by the Guidelines Review Committee. In: WHO Guidelines for Screening and Treatment of Precancerous Lesions for Cervical Cancer Prevention. edn. Geneva: World Health Organization Copyright (c) World Health Organization 2013,; 2013. ISBN: 9789241548694.

6. Miki Y, Swensen J, Shattuck-Eidens D, Futreal PA, Harshman
$\mathrm{K}$, Tavtigian $\mathrm{S}$, et al. A strong candidate for the breast and ovarian cancer susceptibility gene BRCA1. Science. 1994;266(5182):66-71. PMID: 7545954

7. Wooster R, Neuhausen SL, Mangion J, Quirk Y, Ford D, Collins N, et al. Localization of a breast cancer susceptibility gene, BRCA2, to chromosome 13q12-13. Science. 1994;265(5181):2088-90. PMID: 8091231

8. Chen S, Parmigiani G. Meta-analysis of BRCA1 and BRCA2 penetrance. Journal of clinical oncology: official journal of the American Society of Clinical Oncology. 2007;25(11):132933. DOI::10.1200/JCO.2006.09.1066.

9. Dowty JG, Win AK, Buchanan DD, Lindor NM, Macrae FA, Clendenning $\mathrm{M}$, et al. Cancer risks for MLH1 and MSH2 mutation carriers. Hum Mutat. 2013;34(3):490-7. DOI:: 10.1002/humu. 22262 .

10. Bonadona $\mathrm{V}$, Bonaiti B, Olschwang $\mathrm{S}$, Grandjouan $\mathrm{S}$, Huiart $\mathrm{L}$, Longy $\mathrm{M}$, et al. Cancer risks associated with germline mutations in MLH1, MSH2, and MSH6 genes in lynch syndrome. JAMA. 2011;305(22):2304-10. DOI::10.1001/ jama.2011.743. 
11. Pokharel HP, Hacker NF, Andrews L. Changing patterns of referrals and outcomes of genetic participation in gynaecological-oncology multidisciplinary care. Aust N Z J Obstet Gynaecol. 2016;56(6):633-8. DOI::10.1111/ajo.12504.

12. Domchek SM, Friebel TM, Singer CF, Evans DG, Lynch HT Isaacs $\mathrm{C}$, et al. Association of risk-reducing surgery in BRCA1 or BRCA2 mutation carriers with cancer risk and mortality. JAMA. 2010;304(9):967-75. DOI:: 0.1001/jama.2010.1237.

13. Kurian AW, Sigal BM, Plevritis SK. Survival analysis of cancer risk reduction strategies for BRCA1/2 mutation carriers. Journal of clinical oncology: official journal of the American Society of Clinical Oncology. 2010;28(2):222-31. DOI:: 10.1200/JCO.2009.22.7991

14. Schmeler KM, Lynch HT, Chen LM, Munsell MF, Soliman PT, Clark MB, et al. Prophylactic surgery to reduce the risk of gynecologic cancers in the lynch syndrome. N Engl J Med 2006;354(3):261-9. DOI::10.1056/NEJMoa052627

15. De Vos tot Nederveen Cappel WH, Nagengast FM, Griffioen G, Menko FH, Taal BG, Kleibeuker JH, et al Surveillance for hereditary nonpolyposis colorectal cancer: a long-term study on 114 families. Diseases of the colon and rectum. 2002;45(12):1588-94. DOI::10.1097/01 DCR. $0000034502.64985 .3 \mathrm{~F}$
16. Pokharel HP, Hacker NF, Andrews L. Genetic testing in a gynaecological oncology care in developing countriesknowledge, attitudes and perception of Nepalese clinicians Gynecologic oncology research and practice. 2016;3:12. DOI:: 10.1186/s40661-016-0034-5.

17. Piya MK, Acharya SC. Oncology in Nepal. South Asian journal of cancer. 2012;1(1):5-8. DOI:: 10.4103/2278$330 X .96490$.

18. Budhathoki SS, Pokharel PK, Good S, Limbu S, Bhattachan $\mathrm{M}$, Osborne RH. The potential of health literacy to address the health related UN sustainable development goal 3 (SDG3) in Nepal: a rapid review. BMC Health Serv Res. 2017;17(1):237. DOI:: 10.1186/s12913-017-2183-6.

19. Gongal R, Vaidya P, Jha R, Rajbhandary O, Watson M. Informing patients about cancer in Nepal: what do people prefer? Palliat Med. 2006;20(4):471-6. DOI::10.1191/0269216306pm1154oa

20. Dowty JG, Win AK, Buchanan DD, Lindor NM, Macrae FA, Clendenning $\mathbf{M}$, et al. Cancer risks for MLH1 and MSH2 mutation carriers. Hum Mutat. 2013;34(3):490-7. DOI::10.1002/humu.22262. 